\title{
Papers
}

\section{Hospital at home for patients with acute exacerbations of chronic obstructive pulmonary disease: systematic review of evidence}

Felix S F Ram, Jadwiga A Wedzicha, John Wright, Michael Greenstone

\begin{abstract}
Objectives To evaluate the efficacy of hospital at home schemes compared with inpatient care in patients with acute exacerbations of chronic obstructive pulmonary disease (COPD).

Design A systematic review of randomised controlled trials.

Main outcome measure Mortality and readmission to hospital. Results Seven trials with 754 patients were included in the review. Hospital readmission and mortality were not significantly different when hospital at home schemes were compared with inpatient care (relative risk 0.89, 95\% confidence interval 0.72 to 1.12 , and $0.61,0.36$ to 1.05 , respectively). However, compared with inpatient care, hospital at home schemes were associated with substantial cost savings as well as freeing up hospital inpatient beds.

Conclusions Hospital at home schemes can be safely used to care for patients with acute exacerbations of COPD who would otherwise be admitted to hospital. Clinicians should consider this form of management, especially as there is increasing pressure for inpatient beds in the United Kingdom.
\end{abstract}

\section{Introduction}

In the United Kingdom, chronic obstructive pulmonary disease (COPD) continues to be responsible for over 90000 admissions to hospital every year. It is estimated that the mean duration of hospital stay for typical acute exacerbations of chronic obstructive pulmonary disease (AECOPD) is 11 days, which means that about a million hospital bed days a year are taken up in the United Kingdom alone as a result of admissions for COPD. ${ }^{1}$ In addition, age adjusted admission rates for COPD have risen over $50 \%$ in the past nine years. ${ }^{2}$ Acute exacerbations of COPD are the most common cause of admission to hospital for respiratory illness ${ }^{3}$ and they account for about $10 \%$ of all acute medical admissions in the United Kingdom. ${ }^{4}$ This causes an increased demand on hospital beds especially during winter months. The annual cost of COPD to the NHS at 1996-7 prices is around $£ 817.5 \mathrm{~m}(\$ 1505 \mathrm{~m}, € 1222 \mathrm{~m}){ }^{5}$ Admission to hospital accounted for about $35 \%$ of this annual expenditure, despite the fact that less than $2 \%$ of patients with COPD were admitted in the year examined. The cost of a typical hospital admission was estimated as $£ 3000$.

The Royal College of Physicians of London has recommended the provision of respiratory care helpers to improve the management of patients with COPD at home. ${ }^{6}$ Selected patients currently admitted with acute exacerbations of COPD could safely be cared for at home with sufficient support. Mortality from these episodes is closely related to the degree of hypercap- nia and acidosis at admission and to the presence of non-respiratory comorbidities. ${ }^{7-9}$ Many patients presently admitted to hospital do not have these features, and it may be possible to manage them equally well outside the hospital environment.

Hospital at home services are a recent innovation in the management of such acute exacerbations. ${ }^{10}$ The rationale is that such services increase patients' satisfaction and reduce costs without adverse effects on clinical outcome. Evidence in support of such a service is contradictory and has been extrapolated mainly from generic hospital at home schemes. ${ }^{11-14}$ Despite the paucity of objective evidence of efficacy, interest in hospital at home services for acute exacerbations has been considerable, with many respiratory departments establishing their own schemes in the United Kingdom, ${ }^{15}$ Spain, ${ }^{16}$ and Australia. ${ }^{17}$ We conducted a systematic review comparing hospital at home schemes with inpatient care to observe the effects of each type of care on mortality and readmissions to hospital.

\section{Methods}

Types of trials-To be considered for inclusion trials had to study patients presenting to the emergency department with an acute exacerbation who were randomised to either hospital at home or inpatient care. All patients had to be randomised into trials within 72 hours of presenting to the department and after an initial assessment by the hospital medical team. We chose the time limit of 72 hours so that any success with home support could solely be ascribed to this group distinct from inpatient care. Secondly, extending the time limit beyond 72 hours may cause trialists to discharge patients to the home support group who would not have warranted inpatient admission and would have been discharged after a short hospital visit. Such admissions usually require non-medical interventions and are often for social or domestic reasons.

Participants-Patients were not included in the trials if they were deemed obligatory admissions as described in the British Thoracic Society Guidelines. ${ }^{18}$ These include patients with impaired level of consciousness, acute confusion, acute changes on radiography or electrocardiography, arterial $\mathrm{pH}<7.35$, or concomitant medical conditions. Patients attending an emergency department for social reasons were also not considered for inclusion. All remaining patients were considered for hospital at home care.

Interventions-Patients randomised to hospital at home would be under the care of a specialist respiratory nurse (under guidance from the hospital medical team). All patients randomised to hospital at home would be provided with the treatment deemed appropriate at the time of initial assessment and presentation to the emergency department. All hospital at 
home patients should be visited by a respiratory nurse until discharged from care. Patients randomised to inpatient care would be treated as usual and at the discretion of the hospital medical team.

Identification and selection of trials - We identified trials using a predefined search strategy and by searching various relevant databases, including Cochrane controlled trials register, Science Citation Index, Embase, Medline, UK National Research Register, Web of Science, individual respiratory journal websites, and proceedings of the European Respiratory Society, American Thoracic Society, British Thoracic Society, and Thoracic Society of Australia and New Zealand. All searches were completed from database conception up to and including May 2003, and all citations were retrieved without any language restrictions. Trialists and known experts were contacted to obtain any unpublished trials. Two reviewers independently selected trials for inclusion and exclusion. Selection of trials for inclusion in the review was not based on study results but on methodological quality and rigour.

Methodological trial quality assessment-Two reviewers independently assessed the methodological quality of all included trials using the Cochrane approach to assessment of allocation concealment. Trials were scored as either "adequate concealment" (A), "uncertain" (B), or "clearly inadequate concealment" (C).

Data abstraction and analysis-All data were abstracted by using standard forms. Whenever possible, we contacted one author of each included controlled trial to verify the accuracy of the abstracted data and to obtain further information. We combined data from all trials using Review Manager 4.2 (Cochrane Collaboration software). For continuous variables, we pooled trial data using fixed effect weighted mean differences and 95\% confidence intervals. For dichotomous variables, we calculated fixed effect relative risk and 95\% confidence intervals. Heterogeneity among pooled estimates was tested with the DerSimonian and Laird method; $\mathrm{P}<0.05$ was considered significant.

\section{Results}

Search for trials - We included seven randomised controlled trials in the review ${ }^{13} 1617$ 19-22 (fig 1). Two reviewers completely agreed on trial inclusion and quality grading.

Methodological quality of included trials-All included trials stated that the allocation of treatment was randomised. All except one trial ${ }^{17}$ adequately described the allocation concealment method used. We graded six trials as A and one as B. Double blind trial design was not possible because of the nature of the intervention. All except three trials ${ }^{13}{ }^{16} 17$ adequately reported withdrawals and dropouts. The table shows further details of included trials.

Efficacy variables-Included trials reported study outcome measures two to three months after the initial exacerbation. All seven trials with 754 participants provided data on the rate of readmission to hospital (fig 2 ). The rate of readmission to hospital was not significantly different in the hospital at home group compared with the inpatient group (relative risk $0.89,95 \%$ confidence interval 0.72 to 1.12 ). Six trials with 729 participants reported mortality data (fig 3 ). Mortality was not significantly different in the two trial groups $(0.61,0.36$ to 1.05$)$.

Six trials provided data on the number of patients presenting with acute exacerbations of COPD who met the strict trial inclusion criteria. These six trials screened a total of 2786 patients presenting with acute exacerbations, 744 (26.7\%) of whom met the strict study entry criteria. Most of patients who were not eligi-

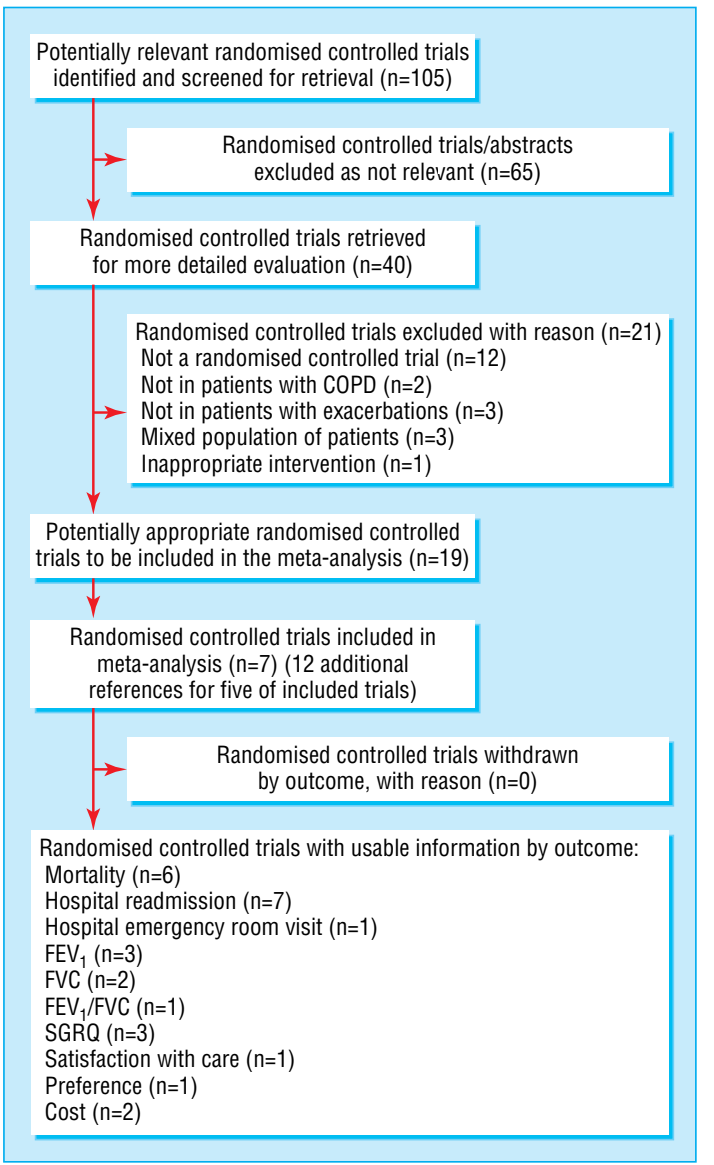

Fig 1 Results of search for trials and reasons for excluding studies

ble for inclusion in the trials required immediate admission, had concomitant medical conditions (including underlying malignancy, pneumothorax, pneumonia, uncontrolled left ventricular failure, acute changes on electrocardiography), or were attending hospital for non-medical reasons.

Four trials reported cost analysis data, which showed substantial savings with hospital at home schemes. Hernandez et $\mathrm{al}^{16}$ and Nicholson et $\mathrm{al}^{17}$ both reported cost savings with hospital at home schemes compared with inpatient care (£533 (\$975, $€ 807)$ and £649 (\$1188, €967) per patient, respectively). Skwarska et al showed that the mean health service cost for hospital at home care was roughly half that of inpatient care (£877 and $£ 1753$, respectively), and the authors went on to conclude that there could also be a notional saving of 433 bed days a year. ${ }^{22}$ Cotton et al reported a saving of 201 bed days a year with hospital at home schemes. ${ }^{19}$

\section{Discussion}

\section{Effectiveness}

In this systematic review we found no significant differences between hospital at home and inpatient care for readmission rates and mortality two to three months after an initial exacerbation of COPD. This suggests that selected patients presenting to emergency departments with acute exacerbations of COPD can be as safely and successfully treated at home as they would as inpatients if they are discharged to home care with support from visiting respiratory nurses and a multidisciplinary team.

Four trials reported substantial savings in costs and bed days with hospital at home schemes. An important issue with these 


\begin{tabular}{|c|c|c|c|}
\hline \multirow[b]{2}{*}{ Study reference } & \multicolumn{2}{|c|}{ Participants' characteristics at baseline } & \multirow[b]{2}{*}{ Intervention } \\
\hline & Inpatient group & $\begin{array}{l}\text { Hospital at home } \\
\text { group }\end{array}$ & \\
\hline Cotton et al ${ }^{19}$ & $\begin{array}{l}\text { Mean age } 68 \text { years, } \\
\mathrm{M} / \mathrm{F} 16 / 24, \mathrm{PaO}_{2} \\
(\mathrm{kPa})=9.2, \mathrm{PaCO}_{2} \\
(\mathrm{kPa})=5.5, \mathrm{FEV}_{1} \\
(\mathrm{~L})=0.94\end{array}$ & $\begin{array}{l}\text { Mean age } 65.7 \text { years, } \\
\mathrm{M} / \mathrm{F} 19 / 22, \mathrm{PaO}_{2}=8.5 \\
\mathrm{PaCO}_{2}=6.0, \mathrm{FEV}_{1}=0.95\end{array}$ & $\begin{array}{l}36 \text { patients underwent } \\
\text { early discharge; } 34 \\
\text { were discharged with } \\
\text { nebulised } \\
\text { bronchodilators and } \\
16 \text { with oxygen. } \\
\text { Median duration of } \\
\text { nurse follow up=24 } \\
\text { days, median No of } \\
\text { nurse visits=11 }\end{array}$ \\
\hline Davies et $\mathrm{a}^{20}$ & $\begin{array}{l}\text { Mean age } 70, \mathrm{M} / \mathrm{F} \\
30 / 20, \mathrm{FEV}_{1}=0.65, \\
\text { respiratory rate }(\mathrm{bpm}) \\
23, \mathrm{pH} 7.39, \\
\mathrm{PaO}_{2}=9.0, \mathrm{PaCO}_{2}=5.2\end{array}$ & $\begin{array}{l}\text { Mean age } 70 \text { years, } \\
\mathrm{M} / \mathrm{F} 45 / 55, \mathrm{FEV}_{1}=0.71 \text {, } \\
\text { respiratory rate } 24 \text {, } \\
\mathrm{pH} 7.4, \mathrm{PaO}_{2}=9.7, \\
\mathrm{PaCO}_{2}=5.2\end{array}$ & $\begin{array}{l}\text { Patients escorted } \\
\text { home by nurses. } \\
\text { Nurses visited } \\
\text { patients mornings and } \\
\text { evenings for } 3 \text { days } \\
\text { and thereafter at } \\
\text { discretion of nurses. } \\
\text { Evening and night } \\
\text { cover provided by } \\
\text { district nurses. If } \\
\text { progress was } \\
\text { unsatisfactory, nurse } \\
\text { or patient could } \\
\text { trigger admission }\end{array}$ \\
\hline Hernandez et al ${ }^{16}$ & $\begin{array}{l}\text { Mean age } 70.5 \text { years, } \\
\mathrm{M} / \mathrm{F} 98 / 3, \text { respiratory } \\
\text { rate }=26.8, \mathrm{PaO}_{2}=8.63 \text {, } \\
\mathrm{PaCO}_{2}=5.84, \mathrm{pH} 7.4\end{array}$ & $\begin{array}{l}\text { Mean age } 71.0 \text { years, } \\
\mathrm{M} / \mathrm{F} 118 / 4, \text { respiratory } \\
\text { rate } 26.9, \mathrm{PaO}_{2}=8.67 \text {, } \\
\mathrm{PaCO}_{2}=5.69, \mathrm{pH} 7.4\end{array}$ & $\begin{array}{l}\text { Patients usually } \\
\text { supervised by primary } \\
\text { care physician who } \\
\text { was not aware of } \\
\text { study protocol. } \\
\text { Median duration of } \\
\text { nurse follow up=8 } \\
\text { weeks, maximum No } \\
\text { of nurse visits=5 }\end{array}$ \\
\hline Nicholson et $\mathrm{al}^{17}$ & \multicolumn{2}{|c|}{$\begin{array}{l}\text { Patient included in trial if aged }>45 \text { years, } \\
\text { diagnosis of COPD, current or former smoker, } \\
\mathrm{FEV}_{1}<60 \% \text { predicted, admission required by } \\
\text { primary care physician or by hospital staff }\end{array}$} & $\begin{array}{l}\text { Patients had nursing } \\
\text { visits on days } 1,2,3 \text {, } \\
\text { and } 7 \text { (days } 4,5 \text {, and } \\
6 \text { were optional) } \\
\text { Allied health } \\
\text { interventions included } \\
\text { dieticians, } \\
\text { occupational therapy, } \\
\text { pharmacy, } \\
\text { physiotherapy, and } \\
\text { psychology }\end{array}$ \\
\hline 0 joo et $\mathrm{al}^{21}$ & $\begin{array}{l}\text { Mean age } 70.1 \text { years, } \\
M / F 15 / 15, F E V_{1} \\
(L)=0.85, F V C=1.83 \text {, } \\
\text { SGRQ total } \\
\text { score }=67.6\end{array}$ & $\begin{array}{l}\text { Mean age } 69.7 \text { years, } \\
M / F \text { 16/14, } F E V_{1}=1.0, \\
F V=1.99, S G R=67.9\end{array}$ & $\begin{array}{l}\text { Patients were } \\
\text { monitored daily by } \\
\text { nurses. Nurses filled } \\
\text { in daily progress and } \\
\text { symptom score charts } \\
\text { for patients in both } \\
\text { study arms. Evening } \\
\text { and night cover was } \\
\text { provided by a direct } \\
\text { line to medical chest } \\
\text { unit }\end{array}$ \\
\hline Shepperd et $\mathrm{al}^{23}$ & - & $\begin{array}{l}\text { Mean age } 71 \text { years, } \\
\text { M/F } 5 / 10 \text {, no data } \\
\text { provided on lung } \\
\text { function }\end{array}$ & $\begin{array}{l}\text { Care included } \\
\text { nursing, } \\
\text { physiotherapy, } \\
\text { occupational therapy, } \\
\text { and pathology. } \\
\text { Patients given mobile } \\
\text { phone }\end{array}$ \\
\hline Skwarska et a $\left.\right|^{22}$ & $\begin{array}{l}\text { Mean age } 69.9 \text { years, } \\
\mathrm{M} / \mathrm{F} 24 / 38, \text { respiratory } \\
\text { rate }=23.2, \mathrm{FEV}_{1}=0.66 \text {, } \\
\text { oxygen } \\
\text { saturation }=91.9 \% \text {, } \\
\mathrm{PaO}_{2}=10.0\end{array}$ & $\begin{array}{l}\text { Mean age } 68.5 \text { years, } \\
\mathrm{M} / \mathrm{F} 63 / 59, \text { respiratory } \\
\text { rate } 22.8, \mathrm{FEV}_{1}=0.77 \text {, } \\
\text { oxygen } \\
\text { saturation }=92 \% \text {, } \\
\mathrm{PaO}_{2}=8.4\end{array}$ & $\begin{array}{l}122 \text { patients } \\
\text { underwent early } \\
\text { discharge. Patients } \\
\text { visited by nurse next } \\
\text { morning and } \\
\text { thereafter at } 2 \text { to } 3 \\
\text { days to monitor need } \\
\text { for treatment }\end{array}$ \\
\hline
\end{tabular}

SGRQ=St George's hospital respiratory questionnaire.

trials was that they did not include weekends in their analysis and this may have underestimated the cost implications. There is also a possibility of publication bias in that by missing unpublished trials or trials with negative results the beneficial effect of hospital at home may have been overestimated. However, we performed a comprehensive systematic search strategy of the literature to identify any potentially relevant studies without any restriction. The systematic strategy used would minimise any biases. We therefore are confident that we identified most of the available research.

\section{Limitations of the review}

One of the disadvantages of comparing hospital at home schemes is the difference in the interventions and how the patients were recruited in each of the trials. The interventions varied from avoiding admission by using respiratory nurses based in an emergency department, through to admission and next day discharge, and early discharge with support at home with or without care from a general practitioner with variable intensity of home support. Due to the paucity of data on costs of these different interventions, we can draw no conclusions about their cost effectiveness. Further research is required to define the optimal level of home support, which should incorporate the "real" and full cost of running such services so that comparisons with inpatient care can be justified.

Additional difficulties with reviewing hospital at home scheme trials involve the inclusion of "distant" outcomes (for example, readmission rates and mortality). This meant we could not obtain information on the speed of recovery after exacerbations and therefore the health burden of the index exacerbation.

Our review, however, indicates that hospital at home schemes are currently not a suitable option for most patients with acute exacerbations of COPD because only one in four of all such patients presenting to hospital could be managed at home with respiratory nurse support. This figure may be an underestimate because of the limited generalisability of the intervention used in the included trials and the strict inclusion criteria in clinical trials-some patients who did not meet the entry criteria may have been suitable for hospital at home schemes. An additional explanation may be that patients were anxious and refused to take part and the difficulty in recruiting acutely ill patients into clinical trials.

Nevertheless, the small percentage of patients discharged early with respiratory nursing support brings with it substantial cost savings both in terms of direct financial cost and the number of hospital bed days freed, and importantly it offers patients' choice. Many admissions for COPD do not occur because of severe exacerbations but because of comorbidities and social circumstances; these patients could safely be managed at home.

\section{Hospital at home schemes in future clinical practice}

As experience and confidence grows with hospital at home schemes and as multidisciplinary organisational arrangements providing such services become harmonised, we will feel more able to discharge patients earlier with nursing and other relevant healthcare support. However, if a patient is to be discharged directly from the emergency department extra safeguards should be considered as the patient should have adequate support to be able to cope at home, the patient should understand the treatment prescribed, and sufficient medication should be supplied to last until the next consultation with their general practitioner or specialist. ${ }^{18}$

\section{Conclusions}

Hospital at home schemes for patients with acute exacerbations of COPD can be used as an alternative to hospital admission and are a safe and effective option for suitable patients. The results of this review should encourage clinicians to consider this form of management. However, it is important that all patients with COPD exacerbations presenting to an emergency department 


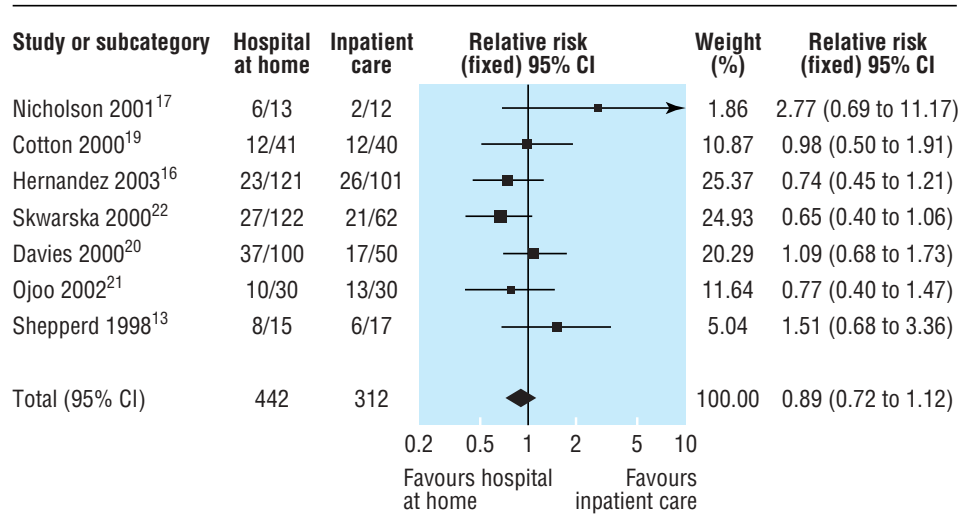

Total events: 123 (hospital at home), 97 (inpatient care)

Test for heterogeneity: $\chi^{2}=7.35, \mathrm{df}=6, \mathrm{P}=0.29$

Test for overall effect: $z=0.98, P=0.33$

Fig 2 Relative risk for readmission to hospital, calculated with fixed effect model with 95\% confidence intervals. Square box indicates relative risk for each trial with line representing $95 \%$ confidence interval

undergo an initial hospital assessment, which is necessary to assess suitability for any hospital at home scheme.

Although our results are promising, there still remains a need for further properly conducted trials in this area. Future trials should include more relevant outcomes including satisfaction, preference, health related quality of life, and the organisational (multidisciplinary, multiagency) arrangements of such schemes that would provide the greatest benefit. Future trials should incorporate an economic evaluation of both indirect and direct costs and describe the resources required to establish hospital at home services.

Future hospital at home schemes need to determine which models or components of delivery of care in which patient groups (severity, complications) delivered by whom (respiratory nurses, generic skills staff) can safely, effectively, and acceptably manage such patients at home.

We thank Jo Picot (research fellow, Wessex Institute for Health Research and Development, University of Southampton) for her assistance with the review; Nicholson and coauthors ${ }^{17}$ for providing further data; and Sheree Wellington for copyediting/proof reading the manuscript.

Contributors: FSFR initiated the idea of the systematic review, wrote the protocol, and conducted the review with input from JW, MG, and JAW at various stages of the review development process. FSFR is guarantor.

Funding: FSFR received a fellowship from the Netherlands Asthma Foundation for the conduct of this review.
Competing interest: None declared.

Ethical approval: Not required.

1 LAIA. Trends in COPD. London: Lung Asthma Information Agency, St George's Hospital Medical School, 2003 (No 1).

2 LAIA. Trends in emergency hospital admissions for lung disease. London: Lung Asthma Information Agency, St George's Hospital Medical School, 2001 (No 4).

3 NHS Executive. Burdens of disease: a discussion document. Leeds: Department of Health, 1996.

4 Kendrick S. The increase in the number of emergency admissions: age, diagnosis, frequency. Wrking paper for the acute beds research group. Edinburgh: Information and Statistics Division, NHSIS, 1994

5 Guest JF. The annual cost of chronic obstructive pulmonary disease to the UK's National Health Service. Dis Manag Health Outcome, 1999;5:93-100.

6 Royal College of Physicians. Disabling chest disease: prevention and care. J R Coll Physicians Lond 1981;15:69-87.

7 Connors AF, Dawson NV, Thomas C, Harrell FE Jr, Desbiens N, Fulkerson WJ, et al. Outcomes following acute exacerbation of severe chronic obstructive lung disease. $\mathrm{Am}$ J Respir Crit Care Med 1996;154:959-67.

8 Jeffrey AA, Warren PM, Flenley DC. Acute hypercapnic respiratory failure in patients with chronic obstructive pulmonary lung disease: risk factors and use of guidelines for management. Thorax 1992;47:37-40.

9 Seneff MG, Wagner DP, Wagner RP, Zimmerman JE, Knaus WA. Hospital and 1-year survival of patients admitted to intensive care units with acute exacerbation of chronic obstructive pulmonary disease. JAMA 1995;274:1852-7.

10 Gravil JH, Al-Rawas OA, Cotton MM, Flanigan U, Irwin A, Stevenson RD. Home treatment of exacerbations of chronic obstructive pulmonary disease by an acute respiratory assessment service. Lancet 1998;351:1853-5.

11 Hughes SL, Ulasevich AA, Weaver FM, Henderson W, Manheim L, Kubal JD, et al. Impact of home care on hospital days: a meta analysis. Health Serv Res 1997:32:415-32. 12 Richards SH, Coast J, Gunnell DJ, Peters TJ, Poundsford J, Darlow MA. Randomised controlled trial comparing effectiveness and acceptability of an early discharge, hospital at home scheme with acute hospital care. BMJ 1998;316:1796-806.

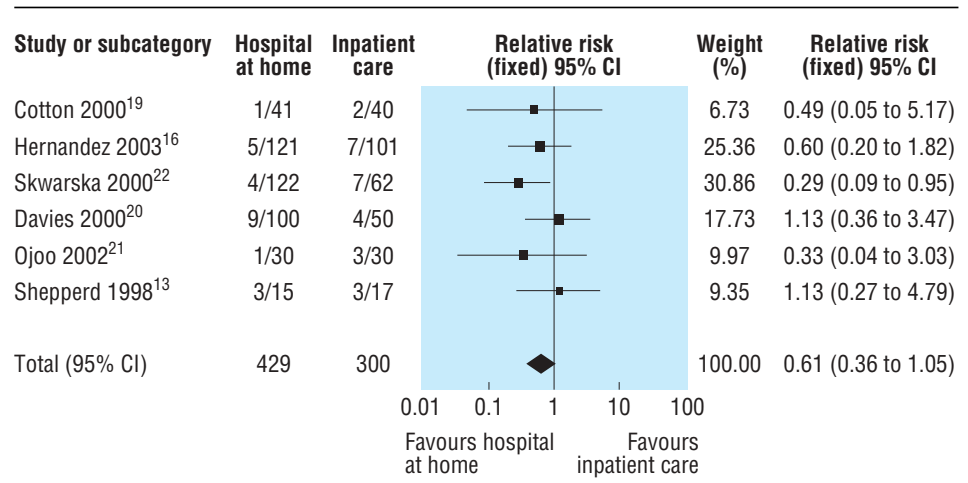

Total events: 23 (hospital at home), 26 (inpatient care)

Test for heterogeneity: $\chi^{2}=3.66, d f=5, P=0.60$

Test for overall effect: $z=1.77, P=0.08$

Fig 3 Details of trials included for mortality outcome 


\section{What is already known on this topic}

Acute exacerbations of COPD are an increasingly common cause of admission to hospital, leading to about 90000 admissions and requiring a million bed days a year

Most patients start to improve within a day or two of initiating standard treatment

Early discharge schemes for patients with less severe exacerbations of COPD are now being widely introduced

\section{What this study adds}

In a systematic review with the primary end points of readmission and death, "hospital at home" care was found to be as safe as inpatient care

Cost analysis data suggests considerable financial savings with this form of care

13 Shepperd S, Harwood D, Gray A, Vessey M, Morgan P. Randomised controlled trial comparing hospital at home care with inpatient hospital care. II: cost minimisation analysis. BMJ 1998;316:1791-6.

14 Wilson A, Parker H, Wynn A, Jagger C, Spiers N, Jones J, et al. Randomised controlled trial of effectiveness of Leicester hospital scheme compared with hospital care. BMJ 1999:319:1542-6.

15 Johnson MK, Flanigan U, Fuld J, Irwin A, Stewart C, Stevenson RD. Hospital at home services for acute exacerbation of chronic obstructive pulmonary disease: a survey of British practice. Health Bull 2001;59:6.

16 Hernandez C, Casas A, Escarrabill J, Alonso J, Puig-Junoy J, Farrero E, et al. Home hospitalisation of exacerbated chronic obstructive pulmonary disease patients. Eur Respir 2003;21:58-67.
17 Nicholson C, Bowler S, Jackson C, Schollay D, Tweeddale M, O'Rourke P. Cost comparison of hospital and home based treatment models for acute chronic obstructive pulmonary disease. Aust Health Rev 2001;24:181-7.

18 British Thoracic Society. British Thoracic Society guidelines for the management of chronic obstructive pulmonary disease. Thorax 1997;52(suppl 5):S1-28

19 Cotton MM, Bucknall CE, Dagg KD, Johnson MK, MacGregor G, Stewart C, et al. Early discharge for patients with exacerbations of chronic obstructive pulmonary disease: a randomized controlled trial. Thorax 2000;55:902-6.

20 Davies L, Wilkinson M, Bonner S, Calverley PM, Angus RM. "Hospital at home" versus hospital care in patients with exacerbations of chronic obstructive pulmonary disease: prospective randomised controlled trial. BMJ 2000;321:1265-8.

21 Ojoo JC, Moon T, McGlone S, Martin K, Gardiner ED, Greenstone MA, et al. Patients' and carers' preferences in two models of care for acute exacerbations of COPD: results of a randomised controlled trial. Thorax 2002:57:167-9.

22 Skwarska E, Cohen G, Skwarski KM, Lamb C, Bushell D, Parker S, et al. Randomized controlled trial of supported discharge in patients with exacerbations of chronic obstructive pulmonary disease. Thorax 2000;55:907-12.

23 Shepperd S, Harwood D, Jenkinson C, Gray A, Vessey M, Morgan P. Randomised controlled trial comparing hospital at home care with inpatient hospital care. I: three month follow up of health outcomes. BMJ 1998;316:1786-91.

(Accepted 12 May 2004)

doi $10.1136 /$ bmj. .38159 .650347 .55

National Collaborating Centre for Women and Children's Health, London NW1 4RG

Felix S F Ram senior research fellow in respiratory medicine

Academic Respiratory Medicine, St Bartholomew's and Royal London School of Medicine and Dentistry, London EC1A 7BE

Jadwiga A Wedzicha professor of respiratory medicine

Department of Epidemiology and Public Health Medicine, Bradford Hospitals NHS Trust, West Yorkshire BD9 6RJ

John Wright consultant in epidemiology and public health medicine

Medical Chest Unit, Castle Hill Hospital, Cottingham, East Yorkshire HU16 5JQ

Michael Greenstone consultant respiratory physician

Correspondence to: F S F Ram fsfram@yahoo.co.uk 